\title{
Responses to Enteric Motor Neurons in the Gastric Fundus of Mice With Reduced Intramuscular Interstitial Cells of Cajal
}

\author{
Kenton M Sanders, Anna K Salter, Grant W Hennig, Sang Don Koh, Brian A Perrino, Sean M Ward and Salah A Baker*
}

Department of Physiology and Cell Biology, University of Nevada School of Medicine, Reno, NV, USA

\begin{abstract}
Background/Aims
Interstitial cells of Cajal (ICC) play important functions in motor activity of the gastrointestinal tract. The role of ICC as pacemakers is well established, however their participation in neurotransmission is controversial. Studies using mutant animals that lack ICC have yielded variable conclusions on their importance in enteric motor responses. The purpose of this study was to: (1) clarify the role of intramuscular ICC (ICC-IM) in gastric motor-neurotransmission and (2) evaluate remodeling of enteric motor responses in $W / W^{V}$ mice.
\end{abstract}

\section{Methods}

Kit immunohistochemistry and post-junctional contractile responses were performed on fundus muscles from wild-type and $W / W^{V}$ mice and quantitative polymerase chain reaction ( $q P C R$ ) was used to evaluate differences in muscarinic and neurokinin receptor expression.

\section{Results}

Although ICC-IM were greatly reduced in comparison with wild-type mice, we found that ICC-IM persisted in the fundus of many W/W $W^{V}$ animals. ICC-IM were not observed in W/WV group $1(46 \%)$ but were observed in W/W group 2 (40\%). Evoked neural responses consisted of excitatory and inhibitory components. The inhibitory component (nitrergic) was absent in W/W group 1 and reduced in W/W group 2. Enhanced excitatory responses (cholinergic) were observed in both W/W $W^{V}$ groups and qPCR revealed that muscarinic- $M_{3}$ receptor expression was significantly augmented in the $W / W^{V}$ fundus compared to wild-type controls.

\section{Conclusions}

This study demonstrates that ICC-IM mediate nitrergic inhibitory neurotransmission in the fundus and provides evidence of plasticity changes in neuronal responses that may explain discrepancies in previous functional studies which utilized mutant animals to examine the role of ICC-IM in gastric enteric motor responses.

\section{(J Neurogastroenterol Motil 2014;20:171-184)}

\section{Key Words}

Enteric nervous system; Interstitial cells of Cajal; Neurotransmission; Muscle relaxation; Muscle, smooth

Received: December 21, 2013 Revised: January 26, 2014 Accepted: January 28, 2014

(c) This is an Open Access article distributed under the terms of the Creative Commons Attribution Non-Commercial License (http://creativecommons. org/licenses/by-nc/3.0) which permits unrestricted non-commercial use, distribution, and reproduction in any medium, provided the original work is properly cited.

*Correspondence: Salah A Baker, PhD

Department of Physiology and Cell Biology, University of Nevada School of Medicine, MS 352, Reno, NV, 89557, USA

Tel: +1-775-682-8844, Fax: +1-775-784-6903, E-mail: sabubaker@medicine.nevada.edu

Financial support: This study was provided by the NIDDK (R01 DK40569) to KMS and by DK57236 to SMW.

Conflicts of interest: None.

Author contributions: Salah A Baker, Grant W Hennig, Sean M Ward and Kenton M Sanders: conception and design of the experiments; Salah A Baker, Grant W Hennig, Anna K Salter, Sang Don Koh, Brian A Perrino, Sean M Ward and Kenton M Sanders: collection, analysis and interpretation of data; Salah A Baker, Sean M Ward and Kenton M Sanders: drafting the article or revising it critically for important intellectual content.

ORCID: Salah A Baker, http://orcid.org/0000-0002-1514-6876. 


\section{Introduction}

Interstitial cells of Cajal (ICC) are distributed throughout the gastrointestinal (GI) tract, and these regulate smooth muscle excitability and contribute to the organization of motility. Two major classes of ICC are identified in most regions of the GI tract: myenteric and intramuscular. Myenteric ICC (ICC-MY) are located close to, but outside, the myenteric plexus between the circular and longitudinal muscle layers. ICC-MY act as pacemakers in the stomach and small intestine and generate electrical slow waves. ${ }^{1-4}$ Intramuscular ICC (ICC-IM) are distributed within smooth muscle bundles of the stomach and within the deep muscular plexus in the small intestine (ICC-DMP). ICC-IM are closely apposed to enteric nerve terminals and form synaptic-like contacts with nerve varicosities. ${ }^{5,6}$ Synaptic proteins are found at sites of close apposition between motor neurons and ICC-IM. ${ }^{7,8}$ These cells are thought to be intermediaries in enteric motor neurotransmission. ${ }^{9,10}$

There is a significant body of information supporting the role of ICC as pacemakers, and the conductance underlying the generation of slow waves has been identified. ${ }^{11-13}$ However, there is considerably more controversy regarding the role of ICC as mediators of enteric motor neurotransmission. Several publications have argued against the role of ICC as intermediaries in motor neurotransmission and suggested that changes in smooth muscle cells (SMCs) or other factors can account for differences in neural responses between wild-type animals and mutants in which ICC-IM are reduced (e.g., $W / W^{V}$ and $S l / S l^{d}$ mice and $W_{s} / W_{s}$ rats $^{14-17}$ ). More recently, using a cell specific Cre-loxP approach, it was concluded that both ICC-IM and smooth muscle are involved in enteric nitrergic neural responses in the fundus. ${ }^{18}$

The lack a particular cell or protein in mutant animals can be compensated during the developmental process and into adulthood, for example endothelial and neuronal nitric oxide synthase (eNOS and nNOS) deficient mice demonstrated mechanisms of physiological compensation. ${ }^{19,20}$ Most studies on the stomach have assumed that ICC-IM are absent in $W / W^{V}$ mice or contain only a few ICC-IM in $W_{s} / W_{s}$ rats. ${ }^{10,14}$ To further evaluate the role of ICC-IM in enteric neurotransmission and the value of $W / W^{V}$ animals for studies of enteric neurotransmission, we revisited the question of enteric motor responses in the fundus of $W / W^{V}$ mice. We have performed a detailed analysis of excitatory and inhibitory contractile responses to neural activation by electrical field stimulation (EFS) and supported these studies with morphological and molecular studies that examined ICC-IM in the same muscles used for contractile responses. We observed two distinct types of responses depending upon the presence or absence of ICC-IM. Further, we demonstrated remodeling of the receptor population involved in excitatory neuromuscular responses and suggest that tissue plasticity or compensation in animals that develop in the absence of ICC-IM might account for the variety of physiological responses reported in $W / W^{V}$ animals.

\section{Materials and Methods}

\section{Animals}

$W / W^{V}$ mice and their wild-type siblings were obtained from the Jackson Laboratory (Bar Harbor, MN, USA). Animals between the ages of 30-60 days (aged-matched) were anaesthetized by inhalation with isoflurane (Baxter, Deerfield, IL, USA) and killed by cervical dislocation.

Animals were maintained in accordance with the National Institutes of Health Guide for the Care and Use of Laboratory Animals. All procedures were approved by the Institutional Animal Use and Care Committee at the University of Nevada.

\section{Tissue Preparation}

Stomachs were removed from mice via an abdominal incision immediately after cervical dislocation and submerged in KrebsRinger bicarbonate solution (KRB). The stomach was opened along the lesser curvature and gastric contents were washed with KRB. The fundus region was identified and isolated ( $3 \mathrm{~mm}$ from the fundus-corpus border) and the mucosa and sub-mucosa layers were removed by sharp dissection. Fundus muscles were divided in half along the greater curvature, one area used for immunohistochemical studies and the other for force measurements.

\section{Drugs and Solutions}

Tissues were maintained and perfused with $\mathrm{KRB}$ containing (mmol/L): NaCl, 120.35; KCl, 5.9; $\mathrm{NaHCO}_{3}, 15.5 ; \mathrm{NaH}_{2} \mathrm{PO}_{4}$, $1.2 ; \mathrm{MgCl}_{2}, 1.2 ; \mathrm{CaCl}_{2}, 2.5$; and glucose, 11.5 . KRB was bubbled with a mixture of $97 \% \mathrm{O}_{2}-3 \% \mathrm{CO}_{2}$ and warmed to $37 \pm 0.2^{\circ} \mathrm{C}$. Atropine, $N^{\omega}$-nitro-l-arginine (L-NNA), neostigmine, sodium nitroprusside and tetrodotoxin (TTX) were purchased from Sigma-Aldrich (St. Louis, MO, USA) and were dissolved in the manufacturer recommended solvent to make stock solutions. 


\section{Mechanical Responses of Stomach Fundus Muscles}

Standard organ bath techniques were employed to measure the changes in force generated by fundus muscles. Muscles (5.0 $\times 9.0 \mathrm{~mm}$ ) were mounted in the circular muscle direction; one end of muscle strip was attached to a fixed mount and the opposite end to an isometric strain gauge (Fort 10; WPI, Sarasota, FL, USA). A resting force of $5.8 \mathrm{mN}$ was applied to set muscles at optimum length, and muscles were allowed to equilibrate for 1 hour. Mechanical responses were recorded on a computer running Acqknowledge 3.2.6 (Biopac Systems, Santa Barbara, CA, USA) and measurements of the area under the curve (AUC) and peak amplitude were obtained. The AUC was determined as the integral values above the baseline of the selected area.

\section{Statistical Analysis}

Data are expressed as means \pm standard errors of the mean (SEM). The " $n$ " values reported in the text refer to the number of fundus muscles used and each muscle strip used in " $n$ " values was taken from a separate animal. The force parameters of the AUC $(\mathrm{mN} \cdot \mathrm{sec})$ and peak amplitude $(\mathrm{mN})$ of the neural responses induced by EFS were analyzed. We performed both forms of measurements AUC and peak amplitude to provide a more complete analysis of the data since several previous studies comparing neuronal responses in muscles from $W / W^{V}$ mice used only one parameter for their analysis. Figures displayed were made from digitized data using Adobe Photoshop 4.0.1 (Adobe Co., Mountain View, CA, USA) and Corel Draw 12.0 (Corel Corp., Ontario, Canada). Statistical significance was calculated using either Student's $t$ test or a one-way ANOVA followed by a post Newman-Keuls test. $P$-values of $<0.05$ were considered to represent significant changes.

\section{Immunohistochemistry}

Whole mounts of fundus tissues were processed for Kit immunohistochemistry from $W / W^{V}$ and wild-type mice. Fundus muscularis tunica was fixed, prepared and visualized as reported previously. ${ }^{21}$ Briefly, tissues were incubated overnight with a goat polyclonal antibody raised against c-kit (ACK2, 1:500 dilution in PBS; R\&D Systems, MN, USA). Immunoreactivity was detected using Alexa-488 labeled donkey anti-goat IgG (1:500 in PBS; Molecular Probes/Invitrogen, NY, USA). Whole mounts were examined using a Zeiss LSM 510 confocal microscope and final images were constructed using Zeiss LSM software.

\section{Volume Analysis}

Confocal stacks were deconvoluted (AutoQuant, Media $\mathrm{Cy}$ bernetics Inc., Bethesda, MD, USA), smoothed $(3 \times 3$ average $)$, threshold and a marching cubes algorithm was applied (Volumetry G7mv, GWH). ${ }^{22}$ The volume of c-Kit positive structures (ICC-IM) was calculated and results are expressed as average \% of the total volume occupying c-Kit positive structures (ICC-IM) throughout the thickness of the external muscle layer.

\section{Molecular Studies}

The relative expression levels of Kit, $\mathrm{M}_{2}, \mathrm{M}_{3}, \mathrm{NK}_{1}$ and $\mathrm{NK}_{2}$ receptors in $W / W^{V}$ and wild-type fundus were determined by quantitative real-time polymerase chain reaction (RT-PCR) performed on a ABI PrismM 7300 sequence detector using SYBR Green chemistry (Applied Biosystems, Foster City, CA, USA). Fundus muscles total RNA and cDNA preparation and amplification were identical to those reported previously. ${ }^{23}$ The following PCR primers were used (the GenBank accession number is given in parentheses): for mouse hypoxanthine guanine phosphoribosyl transferase (HPRT; NM_0133556), nucleotides 289-317 and 459-487; for mouse c-Kit (NM_021099), nucleotides 2739-2759 and 2880-2901; for mouse Chrm2 expression (NM_203491), nucleotides 1045-1067 and 1221-1243; for mouse Chrm3 expression (NM_033269), nucleotides 2475-2494 and 2607-2627; for mouse Tacr1 expression (NM_001159904), nucleotides 200-220 and 328-352; for mouse Tacr2 expression (NM 010648), nucleotides 436-461 and 579-601. Standard curves were generated for murine $c$-Kit, Chrm2, Chrm3, Tacr 1 and Tacr2 receptors and the constitutively expressed HPRT from regression analysis of the mean values of RT-PCRs for the $\log _{10}$ diluted cDNA. Unknown quantities relative to the standard curve for the c-Kit, Chrm2, Chrm3, Tacr1 and Tacr2 primers were calculated, yielding transcriptional quantization of $\mathrm{cDNA}$ relative to the endogenous HPRT. Each cDNA sample was tested in triplicate and cDNA was obtained from 4 different mice.

\section{Results}

\section{Distribution of Intramuscular Interstitial Cells of Cajal in Fundus of Wild-type and $W / W^{V}$ Muscles}

Immunohistochemistry for Kit was used to compare the distribution of ICC-IM in fundus whole mount preparations of wild-type and $W / W^{V}$ muscles (Fig. 1A-F). Spindle-shaped $\mathrm{Kit}^{+}$ 
(ICC-IM) were distributed in the circular and longitudinal muscle layers in wild-type animals (Fig. 1A and 1B). Volume analysis revealed that ICC-IM occupied $29.2 \pm 1.3 \%(\mathrm{n}=12)$ of the muscle layers in wild-type animals (Fig. $1 \mathrm{G}$ ). In comparison, ICC-IM were greatly reduced in fundus muscles of $W / W^{V}$ mice and were observed in only $40 \%$ of the fundus tissues examined. Stomachs of $W / W^{V}$ mice were subsequently divided into 2 groups based on the presence or absence of ICC-IM. $W / W^{V}$ group 1: ICC-IM were not resolved by Kit immunohistochemistry (46\% of muscles, $\mathrm{n}=14$; Fig. $1 \mathrm{C}$ and $1 \mathrm{D})$ and $W / W^{V}$ group 2: ICC-IM were observed (40\% of muscles; Fig. $1 \mathrm{E}$ and $1 \mathrm{~F}$ ). In $W / W^{V}$ group 2 volume analysis revealed that ICC-IM represented $6.9 \pm 1.2 \%$ (Fig. $1 \mathrm{G} ; \mathrm{n}=12$; in comparison to wild-type muscles). The remaining (14\%) of the animals displayed severe mucosal scaring and were not included in further tests.

\section{Post-junctional Neural Responses in Wild-type and $W / W^{V}$ Gastric Fundus}

A comparison of isometric force responses of circular fundus muscles from wild-type and $W / W^{V}$ groups 1 and 2 was performed. Short duration pulses of EFS (1-100 Hz; 0.5 -millisecond duration for 1 second were delivered at supermaximal voltage; Fig. 2A) were applied to activate intrinsic neurons. Mechanical responses to EFS included: (1) contractile responses followed by (2) relaxation responses. Excitatory and inhibitory responses were frequency dependent and blocked by tetrodotoxin $(1 \mu \mathrm{M}$; TTX) at frequencies up to $32 \mathrm{~Hz}$. EFS above this frequency (i.e., $64 \mathrm{~Hz}$ and $100 \mathrm{~Hz}$ ) was not completely blocked by TTX, and therefore may have been partially due to direct stimulation of post-junctional cells. Thus, we only analyzed data for stimuli up to $32 \mathrm{~Hz}$ (Fig. 2A). Fundus muscle strips of wild-type and $W / W^{V}$ mice developed spontaneous tone, and muscle tone was inhibited similarly by sodium nitroprusside $(10 \mu \mathrm{M}$; wild-type $4.68 \pm 0.61 \mathrm{mN} ; W / W^{V} 4.0 \pm 0.54 \mathrm{mN} ; \mathrm{n}=10 ; P$-value $=$ 0.410 , data not shown).

\section{Excitatory responses}

In wild-type fundus, $1 \mathrm{~Hz}$ EFS evoked a contractile response (AUC $0.31 \pm 0.03 \mathrm{mN} \cdot \mathrm{sec}$, peak $0.40 \pm 0.04 \mathrm{mN} ; \mathrm{n}=$ 16; Fig. 2B) and at $8 \mathrm{~Hz}$ (AUC $1.04 \pm 0.16$, peak $0.83 \pm 0.10$ $\mathrm{mN}, \mathrm{n}=16$; Fig. $2 \mathrm{~B}) . W / W^{V}$ groups 1 and 2 fundus muscles showed significantly increased AUC for the excitatory component compared to wild-type fundus muscles (Fig. 3A and supplementary Table 1$) ; W / W^{V}$ group $1(1 \mathrm{~Hz}$ : AUC $1.4 \pm 0.13 ; 8$ Hz: AUC $8.16 \pm 1.15 ; \mathrm{n}=14$; Fig. $2 \mathrm{C})$ and $W / W^{V}$ group $2(1$
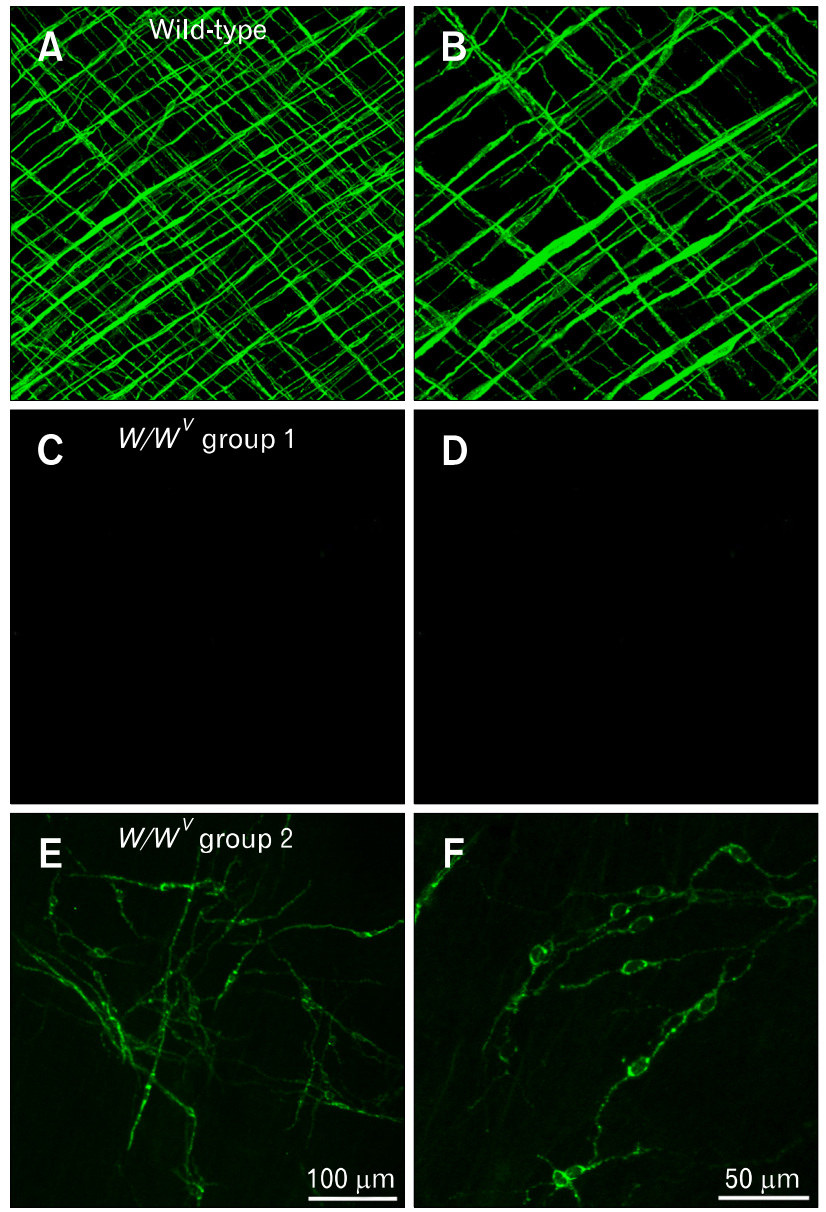

G

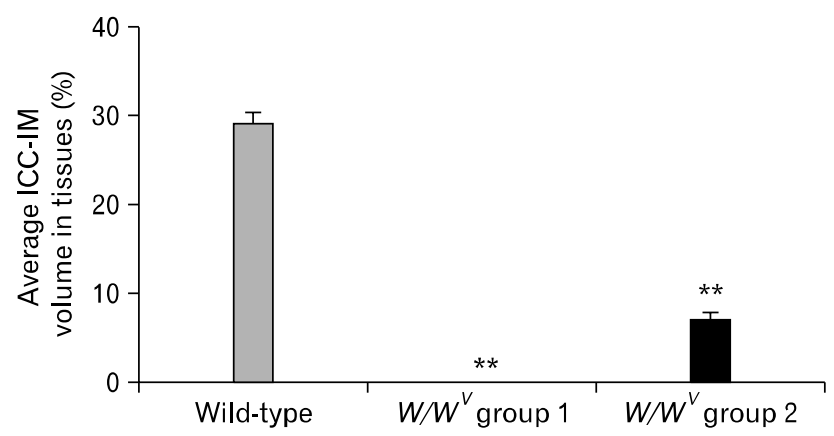

Figure 1. Distribution of Kit + intramuscular interstitial cells of Cajal (ICC-IM) in the murine fundus. (A, B) ICC-IM in circular and longitudinal muscle layers of wild-type muscles at $\times 20$ and $\times 40$ magnifications. $(C, D)$ Absence of ICC-IM in the fundus of $W / W^{V}$ group 1 mice. ICC-IM were absent in both muscle layers. The loss of ICC, and not just the loss of Kit expression, was previously confirmed by electron microscopy. ${ }^{10}$ (E, F) ICC-IM were present in $W / W^{V}$ group 2 mice although the distribution of these cells was not as organized in wild-type. (G) Average volume of ICC-IM plotted as a percentage of total fundus muscle volume $\left({ }^{* *} P<0.001\right)$. ICC-IM were absent in $W / W^{V}$ group 1 but occupied $6.9 \%$ of $W / W^{V}$ group 2 compared to $29 \%$ in wild-type muscles. Scale bar in $\mathrm{E}=100 \mu \mathrm{m}$ and applies to $\mathrm{A}, \mathrm{C}$ and $\mathrm{E}$. Scale bar in $\mathrm{F}=50 \mu \mathrm{m}$ and applies to $\mathrm{B}, \mathrm{D}$ and $\mathrm{F}$. 
A

Stimulation protocol

EFS parameters were ranging from 1 to $32 \mathrm{~Hz}$ with $0.5 \mathrm{~ms}$ duration for $1 \mathrm{sec}$

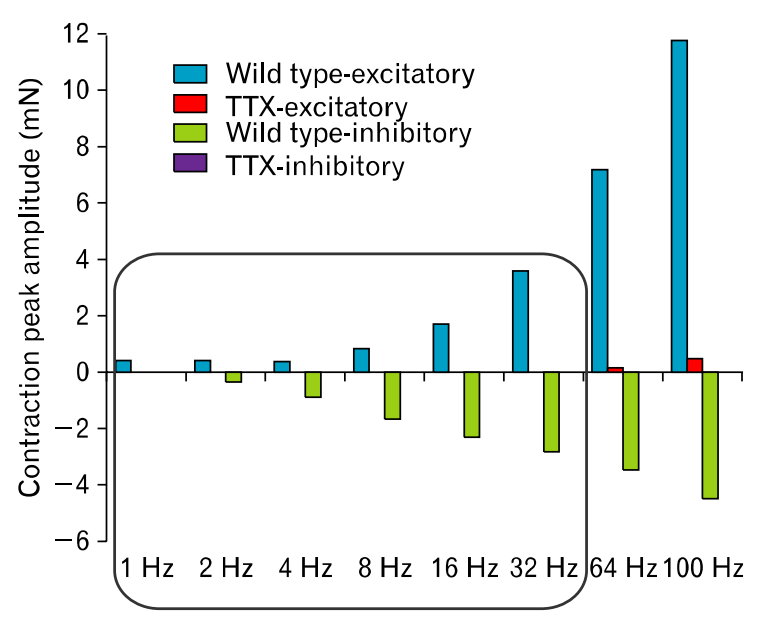

C

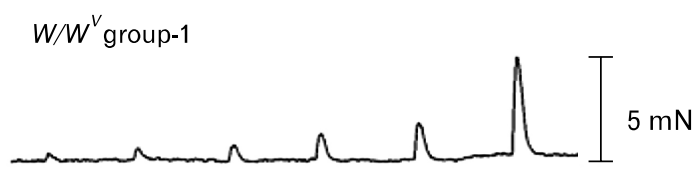

C1 L-NNA $(100 \mu \mathrm{M})$

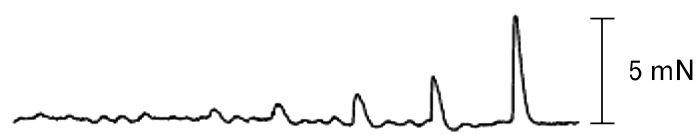

C2 Atropine $(1 \mu \mathrm{M})$ $2 \mathrm{mN}$

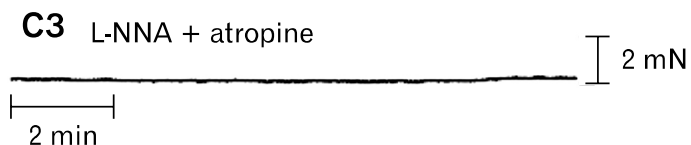

B

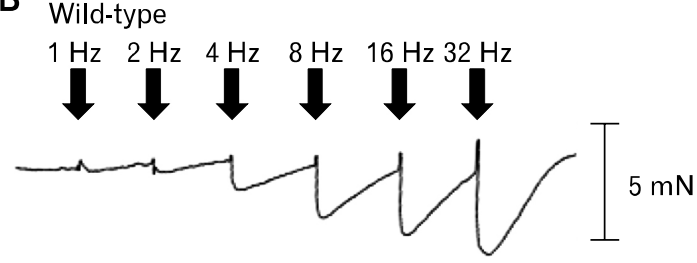

B1 L-NNA $(100 \mu \mathrm{M})$

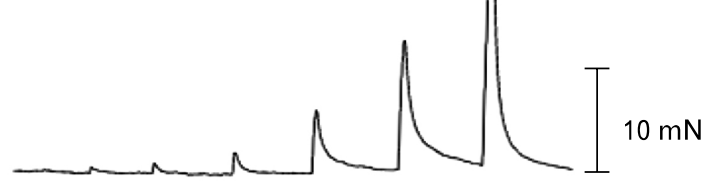

B2 Atropine $(1 \mu \mathrm{M})$

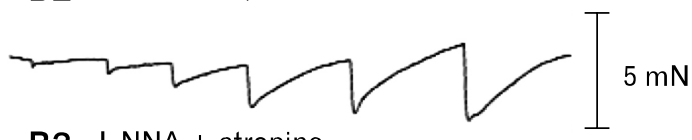

B3 L-NNA + atropine

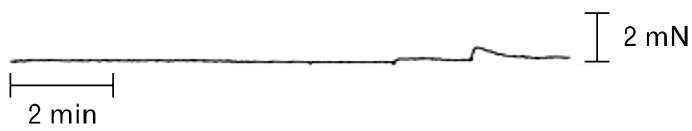

D $w / W^{v}$ group-2
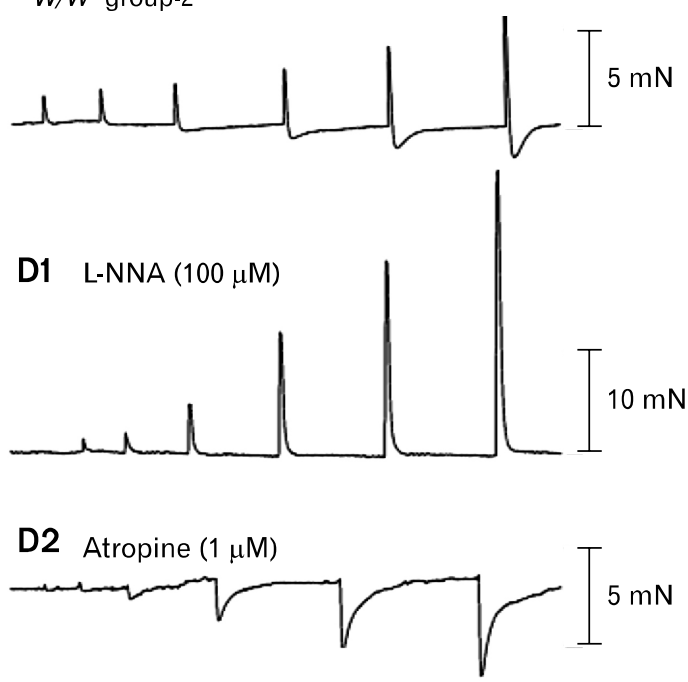

D3 L-NNA + atropine

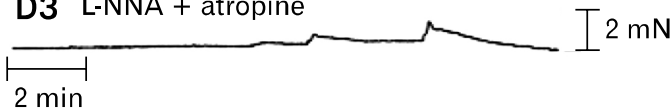

Figure 2. Mechanical responses elicited by electrical field stimulation (EFS) in wild-type and $W / W^{V}$ gastric fundus. (A) Excitatory (blue) and inhibitory (green) responses to EFS (1-32 Hz; 0.5 -millisecond duration for 1 second) were inhibited by tetrodotoxin (TTX, $1 \mu \mathrm{M})$. A small excitatory component persisted in the presence of TTX at $64 \mathrm{~Hz}$ and $100 \mathrm{~Hz}$ (red), and therefore we did not include these frequencies in subsequent analyses. (B) Representative traces of the mechanical responses in wild-type fundus induced by EFS under control conditions (1-32 Hz). (B1) Typical trace in the presence of L-NNA $(100 \mu \mathrm{M})$. (B2) Responses after atropine $(1 \mu \mathrm{M})$ and (B3) responses after the addition of $N^{\omega}$-nitro-l-arginine (L-NNA) and atropine. (C) shows responses from $W / W^{V}$ group 1 under control conditions and typical responses after (C1) L-NNA (100 $\left.\mu \mathrm{M}\right),(\mathrm{C} 2)$ atropine (1 $\left.\mu \mathrm{M}\right)$ and (C3) L-NNA and atropine. (D) Shows typical responses in $W / W^{V}$ group 2 under control conditions (D1) L-NNA (100 $\mu$ M), (D2) atropine (1 $\mu \mathrm{M}$ ) and (D3) L-NNA and atropine. Note the marked differences in mechanical responses to EFS between $W / W^{V}$ group 1 and $W / W^{V}$ group 2 . 
$\mathrm{Hz}$ : AUC $3.71 \pm 0.71 ; 8 \mathrm{~Hz}$ : AUC $8.89 \pm 2.23$; $=12$; Fig. 2D). The peak amplitude of $W / W^{V}$ group 1 muscles demonstrated a tendency toward increase in the excitatory component, however the increase did not reach statistical significance at all frequencies tested compared to wild-type muscles (e.g., $W / W^{V}$ group $1[1 \mathrm{~Hz}]$ : peak $0.27 \pm 0.03 \mathrm{mN} ;[8 \mathrm{~Hz}]$ : peak $1.62 \pm$ $0.23 \mathrm{mN} ; \mathrm{n}=14) . W / W^{V}$ group 2 showed enhanced excitatory peak amplitude at all frequencies except at the highest stimuli 32 $\mathrm{Hz}$ (e.g., $1 \mathrm{~Hz}$ : peak $1.03 \pm 0.18 \mathrm{mN} ; 8 \mathrm{~Hz}$ : peak $2.45 \pm 0.37$ $\mathrm{mN} ; \mathrm{n}=12) . W / W^{V}$ group 1 showed reduced excitatory AUC and peak amplitude in comparison to $W / W^{V}$ group 2 at low frequencies (1-4 Hz) and no significant difference at higher frequencies. A summary of analysis of contractile responses at all frequencies is shown in Fig. 3 and supplementary Table 1.

Atropine $(1 \mu \mathrm{M})$ abolished the excitatory contractions at all EFS frequencies in wild-type fundus muscles except for $0.2 \%$ of the excitatory AUC at $32 \mathrm{~Hz}$ (Fig. 3A and 3B), providing evidence that excitatory neurotransmission in the gastric fundus is predominantly cholinergic with the stimulus parameters used. Atropine also blocked the excitatory component of responses to EFS in $W / W^{V}$ group 1 muscles at low frequencies $(1 \mathrm{~Hz}$ and 2 $\mathrm{Hz}$ ), however, a very small resistant excitatory component less than $3.3 \%$ of $W / W^{V}$ group 1 contraction was observed at higher frequencies (e.g., $8 \mathrm{~Hz}$ : AUC $0.27 \pm 0.06$, peak $0.13 \pm 0.01$ $\mathrm{mN} ; \mathrm{n}=7$; Fig. 3). Atropine blocked the majority of the excitatory response in $W / W^{V}$ group 2 fundus muscles, and a small atropine-resistant component less than $7.5 \%$ of $W / W^{V}$ group 2 contraction was observed at all frequencies (e.g., $1 \mathrm{~Hz}$ : AUC 0.28 \pm 0.15 , peak $0.17 \pm 0.09 \mathrm{mN} ; 8 \mathrm{~Hz}$ : AUC $0.08 \pm 0.07$, peak $0.08 \pm 0.048 \mathrm{mN}$; $=7$; Fig. 3 and supplementary Table 1).

L-NNA $(1 \mu \mathrm{M})$ significantly increased the EFS induced contraction at all frequencies in wild-type fundus (e.g., $1 \mathrm{~Hz}$ : AUC $3.41 \pm 0.81$, peak $0.73 \pm 0.06 \mathrm{mN} ; 8 \mathrm{~Hz}$ : AUC $32.85 \pm$ 6.20 , peak $5.88 \pm 0.64 \mathrm{mN} ; \mathrm{n}=8$; Fig. $3 \mathrm{~A}$ and $3 \mathrm{~B}$ ), indicating a powerful overlay of nitrergic inhibitory effects in response to EFS when NOS was not blocked. In $W / W^{V}$ group 1, L-NNA failed to produce any significant increase in excitatory responses, except at $32 \mathrm{~Hz}$ in comparison to $W / W^{V}$ group 1 where no drugs were added (Fig. 3A and 3B). Compared to wild-type muscles, in the presence of L-NNA $W / W^{V}$ group 1 demonstrated a significantly lower AUC and peak contractions at all frequencies (e.g., $1 \mathrm{~Hz}$ : AUC $0.28 \pm 0.10$, peak $0.08 \pm 0.03 \mathrm{mN}$; $8 \mathrm{~Hz}$ : AUC $10.63 \pm 2.30$, peak $1.66 \pm 0.41 \mathrm{mN} ; \mathrm{n}=7$; Fig. $3 \mathrm{~A}$ and $3 \mathrm{~B}$, and supplementary Table 2 ). The inability of L-NNA to enhance excitatory responses in $W / W^{V}$ group 1 suggests reduced nitrergic responses in gastric fundus muscles in the absence of ICC-IM.

Addition of L-NNA to fundus muscles of $W / W^{V}$ group 2 (with retention of ICC-IM) resulted in inhibition of the excitatory component at low frequencies of EFS (e.g., $1 \mathrm{~Hz}$ : AUC $1.30 \pm 0.37$, peak $0.41 \pm 0.09 \mathrm{mN} ; \mathrm{n}=6)$ and increased excitatory responses at higher frequencies (e.g., $8 \mathrm{~Hz}$ : AUC 24.30
A

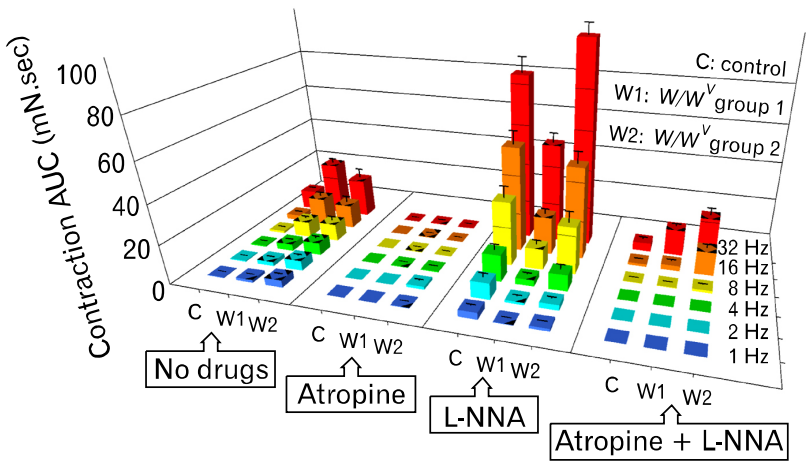

B

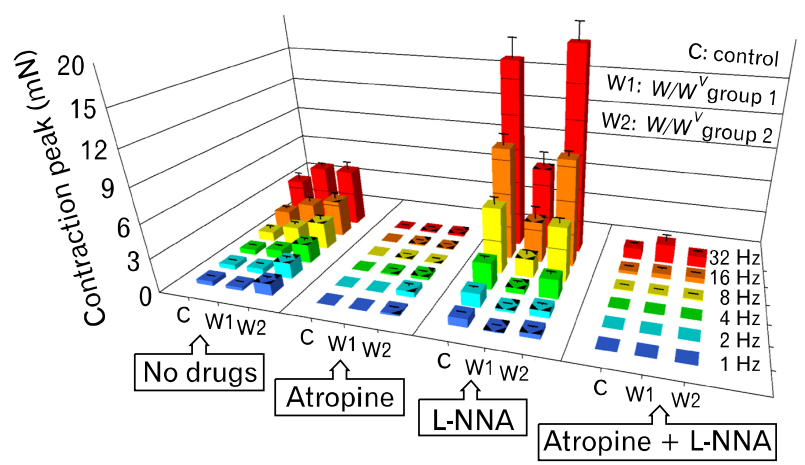

Figure 3. Summary of excitatory responses in wild-type and $W / W^{V}$ fundus to electrical field stimulation (EFS). (A) Representative bar graphs of the mean values of the area under the curve (AUC; $\mathrm{mN} \cdot \mathrm{sec}$ ) and (B) Representative bar graphs of the mean peak amplitudes ( $\mathrm{mN}$ ) of the contractile responses to EFS $(1-32 \mathrm{~Hz})$ in wild-type and both $W / W^{V}$ groups 1and 2. The average AUC and peak contractile amplitudes were calculated in the presence of atropine $(1 \mu \mathrm{M}), N^{\omega}$-nitro-l-arginine (L-NNA, $\left.100 \mu \mathrm{M}\right)$ and in the presence of both L-NNA and atropine together from each control mice (C) and $W / W^{V}$ group 1 (W1) and $W / W^{V}$ group 2 (W2) fundus. Note the large increases in contraction after L-NNA in wild-type and $W / W^{V}$ group 2 muscles, but very small increase in contractile responses after L-NNA in $W / W^{V}$ group 1 muscles. These observations indicate that very little nitrergic regulation occurs in the absence of intramuscular interstitial cells of Cajal. Note in the bar graphs the 1 triangle indicates a $P$-value $<0.05$, 2 triangles indicate a $P$-value $<0.01$ and 3 triangles indicate a $P$-value $<0.001$. 
\pm 5.83, peak $4.90 \pm 0.46 \mathrm{mN} ; \mathrm{n}=6$; Fig. $3 \mathrm{~A}$ and $3 \mathrm{~B}$ ) compared with $W / W^{V}$ group 2 where no drugs were added. Compared to wild-type muscles, in the presence of L-NNA there was a tendency toward reduction in the excitatory component AUC, however the reduction did not reach statistical significance at all frequencies of EFS. The excitatory component peak demonstrated similar results to AUC with the exception that there was a significant reduction of excitatory contractile peak responses at low frequencies $(1 \mathrm{~Hz}$ and $2 \mathrm{~Hz})$ only in the presence of L-NNA (Fig. 3A and 3B, and supplementary Table 2).

Addition of L-NNA and atropine together abolished the excitatory component elicited by EFS application at lower frequencies (1-4 Hz) and significantly reduced the response at higher frequencies in wild-type and in both $W / W^{V}$ groups. Wild-type (8 $\mathrm{Hz}$ : AUC $0.14 \pm 0.07$, peak $0.06 \pm 0.03 \mathrm{mN} ; \mathrm{n}=16), W / W^{V}$ group $1(8 \mathrm{~Hz}$ : AUC $0.24 \pm 0.10$, peak $0.08 \pm 0.03 \mathrm{mN} ; \mathrm{n}=$ $14)$, and $W / W^{V}$ group 2 (8 Hz: AUC $1.19 \pm 0.69$, peak $0.10 \pm$ $0.05 \mathrm{mN}$; $=12$; Fig. $3 \mathrm{~A}$ and $3 \mathrm{~B}$, and supplementary Table 2).

\section{Inhibitory responses}

EFS evoked prominent frequency-dependent relaxations in wild-type fundus $(1 \mathrm{~Hz}$ : AUC $0.05 \pm 0.03$, peak $0.07 \pm 0.03$ $\mathrm{mN} ; 8 \mathrm{~Hz}$ : AUC $29.2 \pm 2.49$, peak $1.79 \pm 0.18 \mathrm{mN}$; $=16$ ) (Fig. $4 \mathrm{~A}$ and $4 \mathrm{~B}$ ). Fundus muscles from $W / W^{V}$ group 1 lacked relaxation responses to EFS at all frequencies tested. Fundus muscles from $W / W^{V}$ group 2 lacked inhibitory relaxations in re-

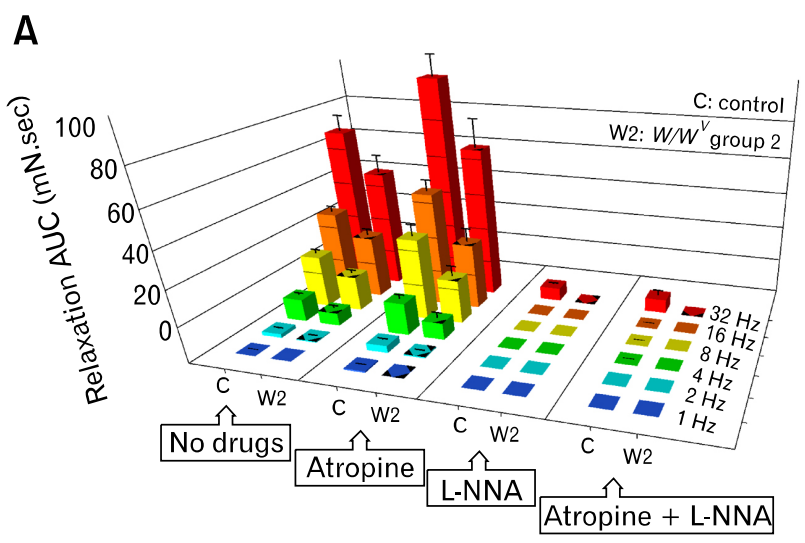

sponse to $1 \mathrm{~Hz}$ of EFS and displayed greatly attenuated responses to higher EFS frequencies (8 Hz: AUC $19.62 \pm 1.86$, peak $0.99 \pm 0.12 \mathrm{mN} ; \mathrm{n}=12$ ) compared to wild-type muscles (Fig. 4A and 4B, and supplementary Table 3). The absence of inhibitory responses when ICC-IM were absent and reduced responses when ICC-IM were present in reduced numbers, provide evidence for the role of ICC-IM in mediating inhibitory neurotransmission in the gastric fundus.

After the addition of atropine $(1 \mu \mathrm{M})$, EFS induced frequency-dependent relaxation in wild-type fundus ( $1 \mathrm{~Hz}$ : AUC $0.73 \pm 0.13 ; 8 \mathrm{~Hz}$ : AUC $45.84 \pm 6.50 ; \mathrm{n}=8$; Fig. $4 \mathrm{~A}$ and $4 \mathrm{~B})$. Although there was an increase in the relaxation AUC, there was no significant increase in the maximal amplitude of relaxations, except at $1 \mathrm{~Hz}$ stimulation $(1 \mathrm{~Hz}$ : peak $0.28 \pm 0.04 \mathrm{mN}$; 8 Hz: peak $2.03 \pm 0.14 \mathrm{mN}$; $=8$; Fig. $4 \mathrm{~A}$ and 4B) compared to wild-type controls with no drugs added. In $W / W^{V}$ group 1 , relaxations were absent in the presence of atropine, and in $W / W^{V}$ group 2 muscles the inhibitory responses were not elicited by a 1 $\mathrm{Hz}$ stimulation in the presence of atropine and there was no significant difference in relaxation responses compared to $W / W^{V}$ group 2 where no drugs were added (e.g., $8 \mathrm{~Hz}$ : AUC $24.8 \pm$ 5.69 , peak $1.30 \pm 0.31 \mathrm{mN} ; \mathrm{n}=12$; Fig. $4 \mathrm{~A}$ and $4 \mathrm{~B}$ ). In comparison to wild-type muscles, $W / W^{V}$ group 2 inhibitory responses were significantly attenuated at all frequencies of stimulation in the presence of atropine (Fig. $4 \mathrm{~A}$ and $4 \mathrm{~B}$, and supplementary Table 3).

B

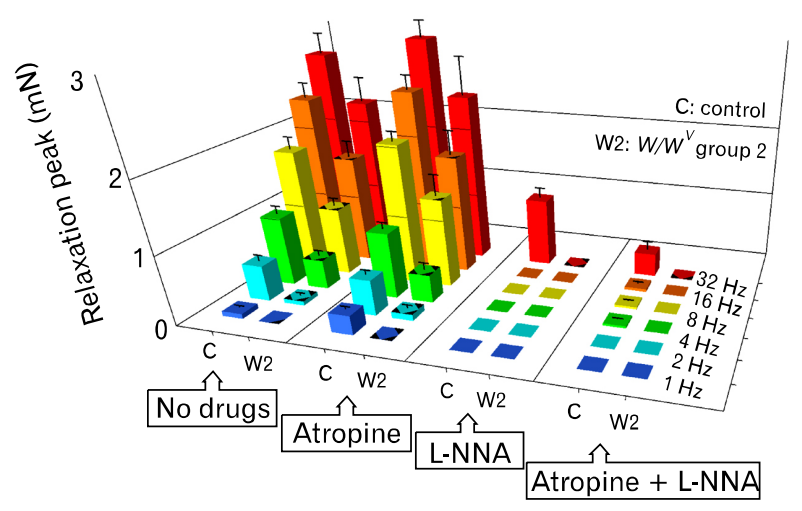

Figure 4. Summary of the inhibitory responses to electrical field stimulation (EFS) in wild-type and $W / W^{V}$ gastric fundus. (A) Bar graphs summary of the mean values of the area under the curve (AUC; $\mathrm{mN} \cdot \mathrm{sec})$ and $(\mathrm{B})$ represent mean peaks amplitude $(\mathrm{mN})$ of the inhibitory responses to EFS in wild-type control mice (C) and $W / W^{V}$ group 2 (W2). Mean inhibitory AUC and peak relaxations were calculated in the presence of atropine $(1 \mu \mathrm{M})$, $N^{\omega}$-nitro-l-arginine (L-NNA, $\left.100 \mu \mathrm{M}\right)$ and in the presence of atropine and L-NNA together in wild-type and $W / W^{V}$ fundus (A, B); inhibitory responses were significantly inhibited by L-NNA in wild-type muscles but a small relaxation persisted at higher frequencies (i.e., $32 \mathrm{~Hz}$ ). (A, B) Relaxation responses were completely inhibited by L-NNA in $W / W^{V}$ group 2 fundus. $W / W^{V}$ group 1 did not have inhibitory responses and were not included in the analysis. Note in the bar graphs the 1 triangle indicates a $P$-value $<0.05,2$ triangles indicate a $P$-value $<0.01$ and 3 triangles indicate a $P$-value $<0.001$. 
A

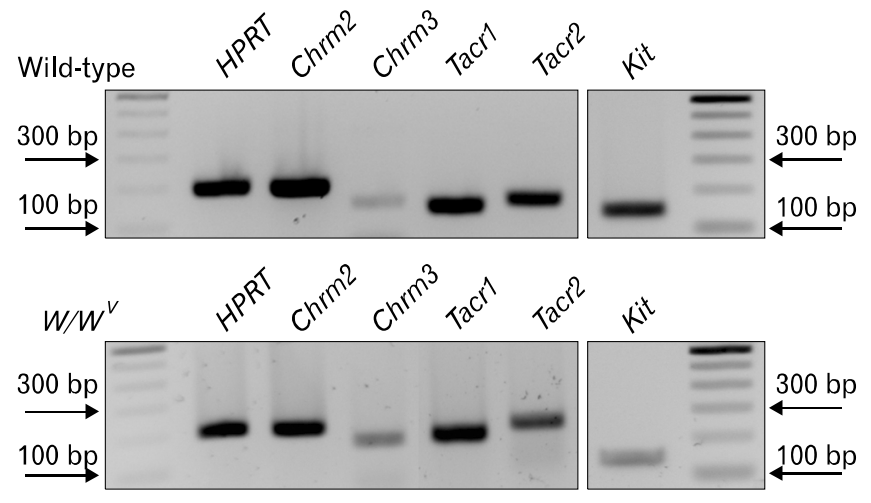

B

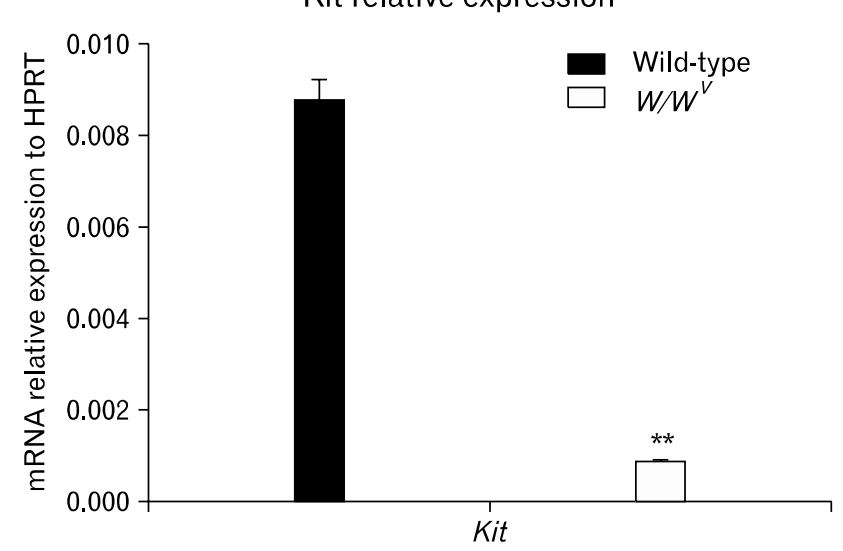

D

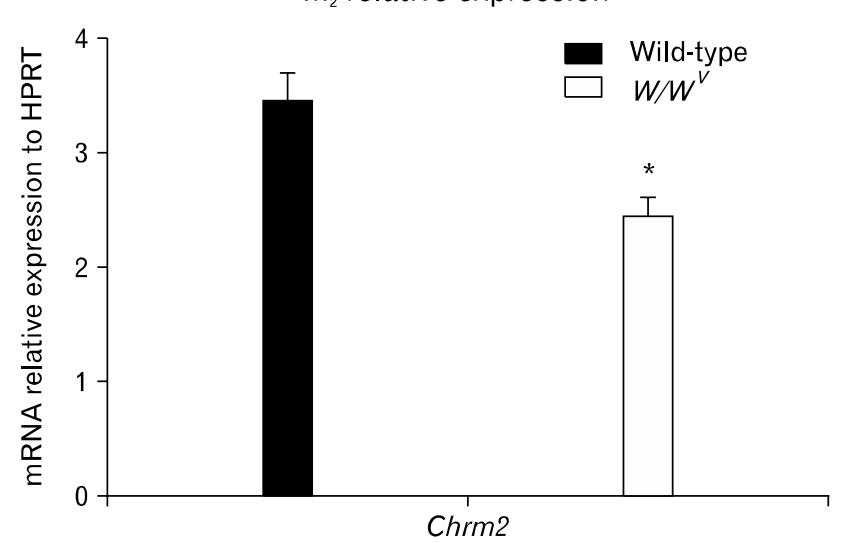

C

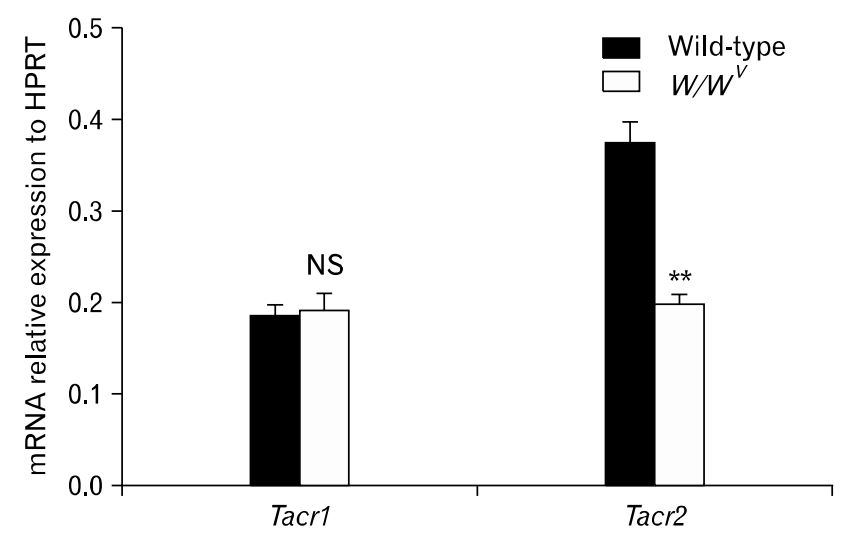

E $M_{3}$ relative expression

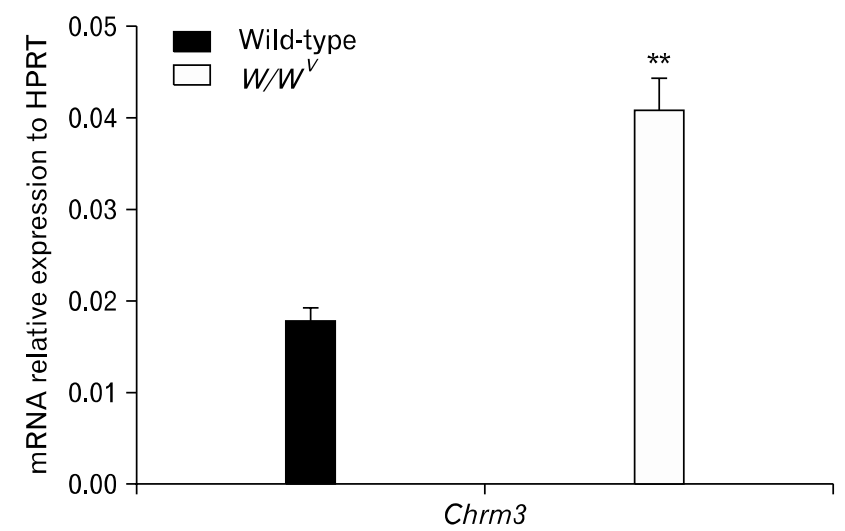

Figure 5. Transcriptional changes in muscarinic $\left(\mathrm{M}_{2}\right.$ and $\left.\mathrm{M}_{3}\right)$ and neurokinin $\left(\mathrm{NK}_{1}\right.$ and $\left.\mathrm{NK}_{2}\right)$ receptor expression in the $W / W^{V}$ gastric fundus. $(\mathrm{A})$ Representative gels displaying amplification products from gastric fundus-derived RNA using gene specific primers for Kit, Chrm 2, Chrm 3 ( $\mathrm{M}_{2}$ and $\mathrm{M}_{3}$ receptors), Tacr1 and Tacr $2\left(\mathrm{NK}_{1}\right.$ and $\mathrm{NK}_{2}$ receptors) in wild-type and $W / W^{V}$ animals. Note that the polymerase chain reaction (PCR) gel is not quantitative. (B) Quantitative PCR (q-PCR) revealed decreased levels of Kit transcripts in $W / W^{V}$ fundus compared to wild-type $\left({ }^{* *} P<0.001\right)$. (C) q-PCR showed that Tacr $1\left(\mathrm{NK}_{1}\right.$ receptor) expression was not significantly different between wild-type and $W / W^{V}$ mice, whereas Tacr2 $\left(\mathrm{NK}_{2}\right)$ was significantly reduced in $W / W^{V}$ fundus $\left({ }^{* *} P<0.001\right)$. (D) $C h r m 2\left(\mathrm{M}_{2}\right.$ receptors) showed significant reduction in their expression in $W / W^{V}$ muscles $\left({ }^{*} P<0.05\right)$. (E) Chrm $3\left(\mathrm{M}_{3}\right)$ showed a significant increase $W / W^{V}$ fundus compared to wild-type muscles $\left({ }^{* *} P<0.001\right)$. Hypoxanthine guanine phosphoribosyl transferase (HPRT) was used as a house-keeping gene. NS, not significant. 
L-NNA $(100 \mu \mathrm{M})$ inhibited relaxation responses to EFS in wild-type and $W / W^{V}$ group 2 muscles at frequencies less than 32 $\mathrm{Hz}$ (Fig. 4A and 4B). A small inhibitory response was resistant to L-NNA at $32 \mathrm{~Hz}$ in wild-type muscles ( $32 \mathrm{~Hz}$ : AUC $7.39 \pm$ 0.80 , peak $1.00 \pm 0.15 \mathrm{mN} ; \mathrm{n}=6$; Fig. $4 \mathrm{~A}$ and $4 \mathrm{~B}$, and supplementary Table 4). Combination of L-NNA and atropine inhibited relaxation responses to EFS in wild-type muscles $(1 \mathrm{~Hz}$ : AUC 0, peak $0 \mathrm{mN}$; $8 \mathrm{~Hz}$ : AUC $0.03 \pm 0.02$, peak $0.03 \pm 0.12$
$\mathrm{mN} ; \mathrm{n}=6$; Fig. $4 \mathrm{~A}$ and $4 \mathrm{~B}$ ) and abolished responses in $W / W^{V}$ group 2 muscles (Fig. 4A and 4B, and supplementary Table 4).

\section{Changes in Excitatory Receptor Expression in $W / W^{V}$ Gastric Fundus}

Enhanced excitatory responses to EFS were observed in $W / W^{V}$ muscles in the absence of ICC-IM or when ICC-IM were reduced in numbers. Therefore, we evaluated whether fundus
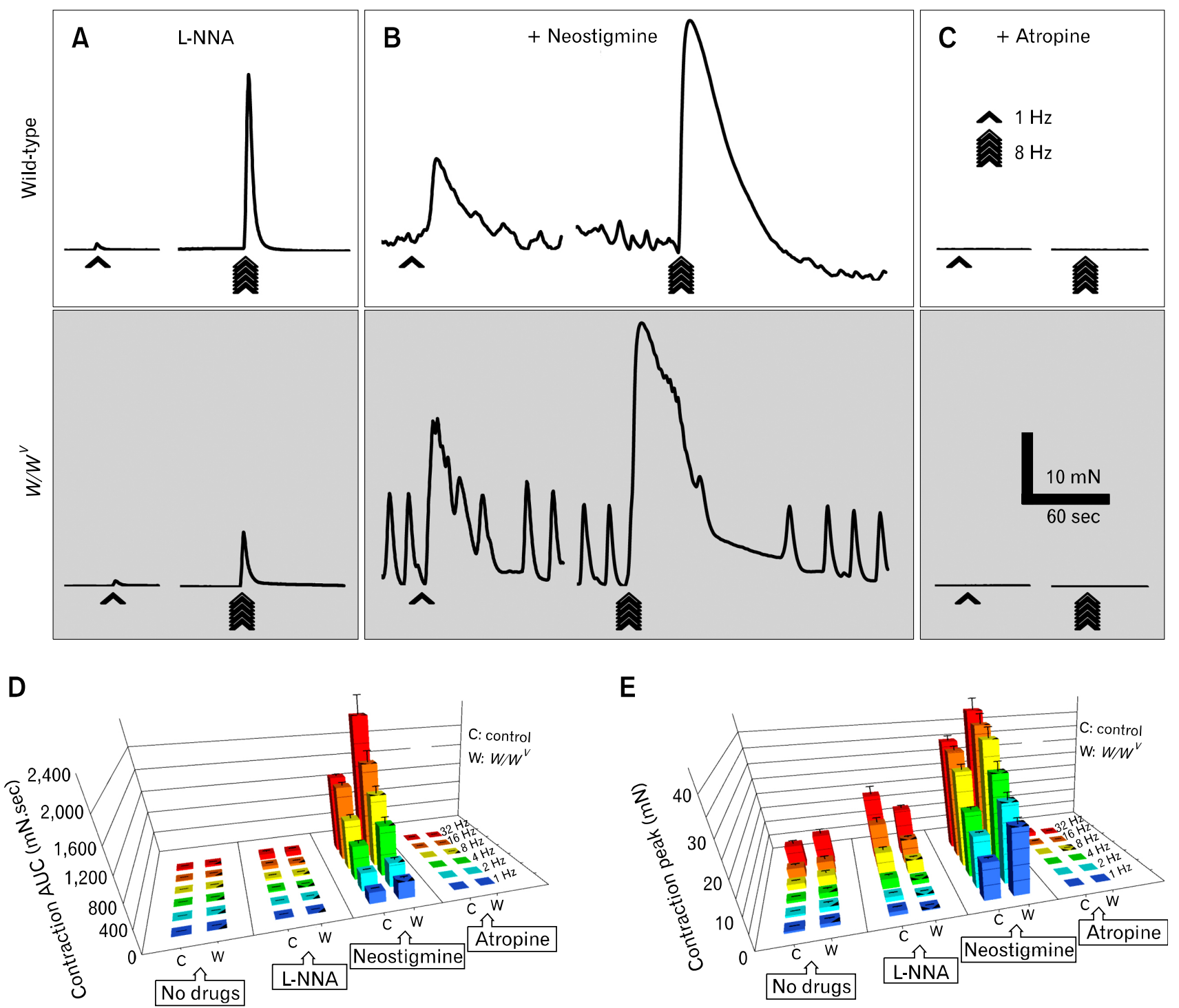

Figure 6. Metabolic degradation of acetylcholine in $W / W^{V}$ fundus. (A) Representative traces of the mechanical responses in wild-type (white box) and $W / W^{V}$ (gray box) fundus induced by electrical field stimulation (EFS) in the presence of $N^{\omega}$-nitro-l-arginine (L-NNA, $\left.100 \mu \mathrm{M}\right), \mathrm{L}-\mathrm{NNA}$ and the cholinesterase inhibitor, neostigmine $(3 \mu \mathrm{M})(\mathrm{B})$ and L-NNA, neostigmine and atropine $(1 \mu \mathrm{M})$ together $(\mathrm{C})$. Bar graphs represent the area under the curve (AUC) values (D) and peak amplitudes (E) of the excitatory responses to EFS in wild-type control mice (C) and $W / W^{V}$ (W) fundus, respectively. There were significantly greater contractions in $W / W^{V}$ muscles compared to wild-type. Note in the bar graphs the 1 triangle indicate a $P$-value $<0.05,2$ triangles indicate a $P$-value $<0.01$ and 3 triangles indicate a $P$-value $<0.001$. 
muscles of $W / W^{V}$ animals might have increased expression of receptors for excitatory neurotransmitters (Fig. 5A). We confirmed immunohistochemistry results by showing reduced Kit transcripts in $W / W^{V}$ muscles. Kit expression was reduced from 0.009 \pm 0.00004 in wild-type muscles versus $0.0009 \pm 0.0001$ in $W / W^{V}$ muscles relative to HPRT expression $(\mathrm{n}=4$, Fig. $5 \mathrm{~B})$. Examination of $\mathrm{M}_{2}$ and $\mathrm{M}_{3}$ muscarinic receptor expression revealed that $\mathrm{M}_{2}$ receptor transcripts $(C h r m 2)$ were decreased in $W / W^{V}$ muscles in comparison to wild-type tissues $(2.39 \pm 0.22$ vs. $3.42 \pm 0.24$, respectively; $\mathrm{n}=4$; Fig. $5 \mathrm{D})$, whereas $\mathrm{M} 3$ receptor (Chrm3) expression was significantly enhanced in $W / W^{V}$ versus wild-type tissues $(0.04 \pm 0.003$ vs. $0.017 \pm 0.001$, respectively; $\mathrm{n}=4$; Fig. $5 \mathrm{E}$ ). We also investigated changes in the expression of neurokinin receptors $\left(\mathrm{NK}_{1}\right.$ and $\left.\mathrm{NK}_{2}\right)$ in $W / W^{V}$ versus wild-type muscles. $\mathrm{NK}_{1}$ transcripts (Tacr1) showed no significant change whereas $\mathrm{NK}_{2}$ transcripts (Tacr2) were decreased in $W / W^{V}$ fundus (Tacr1: $0.19 \pm 0.02$ versus $0.19 \pm 0.01$; Tacr2: $0.20 \pm 0.01$ versus $0.37 \pm 0.02$ respectively; $n=4$; Fig. $5 \mathrm{C}$ ) Changes in excitatory receptor expression in $W / W^{V}$ versus wild-type fundus indicate compensatory remodeling of the neuroeffector receptors in the $W / W^{V}$ animals.

\section{Degradation of Acetylcholine in $W / W^{V}$ Fundus}

In the absence of ICC-IM, there may also be changes in the degradation rate of acetylcholine (ACh) due to loss of the small junctional volumes created by close apposition of ICC-IM with nerve varicosities in which ACh concentration might be very high in wild-type mice. We investigated the effects of neostigmine, an acetylcholine esterase inhibitor, on tone and excitatory responses of wild-type and $W / W^{V}$ fundus muscles. In the presence of L-NNA (Fig. 6 and supplementary Table 5), neostigmine (3 $\mu \mathrm{M}$ ) increased baseline tone and contractile responses (e.g., 1 $\mathrm{Hz}$ : AUC $204.10 \pm 7.30$, peak $12.10 \pm 0.43 \mathrm{mN}$; $8 \mathrm{~Hz}$ : AUC $910.00 \pm 67.40$, peak $31.00 \pm 1.67 \mathrm{mN} ; \mathrm{n}=6$ ) in wild-type muscles at all frequencies tested (Fig. $6 \mathrm{~B}$ and supplementary Table 6). Further addition of atropine $(1 \mu \mathrm{M})$ abolished all but a small remnant contraction at 16 and $32 \mathrm{~Hz}(32 \mathrm{~Hz}$ : AUC 10.30 \pm 4.30 , peak $1.33 \pm 0.59 \mathrm{mN}$; $\mathrm{n}=6$; Fig. $6 \mathrm{C}$ and supplementary Table 6). In $W / W^{V}$ muscles neostigmine significantly increased basal tone and contractile responses at all frequencies tested (1 Hz: AUC 304.80 \pm 31.00 , peak $21.50 \pm 1.90 \mathrm{mN}$; 8 $\mathrm{Hz}$ : AUC $1308.00 \pm 127.00$, peak $39.90 \pm 3.20 \mathrm{mN}$; $\mathrm{n}=6$; Fig. 6B, gray box) and these responses were abolished by atropine similar to wild-type (Fig. 6C, gray box). Comparison of con- tractile responses showed that changes in baseline tone after neostigmine were not significantly different in wild-type and $W / W^{V}$ muscles (wild-type: $20.00 \pm 1.73 \mathrm{mN} ; W / W^{V}: 16.80 \pm 1.36$ $\mathrm{mN} ; \mathrm{n}=6, P$-value $=0.190$, data not shown). Contractile responses to EFS after neostigmine, however, were significantly greater in $W / W^{V}$ tissues than in wild-type muscles (Fig. 6D and $6 \mathrm{E}$, and supplementary Table 6).

\section{Discussion}

Evidence supporting the idea that ICC-IM mediate enteric motor responses in the GI tract has been based mainly on morphological and functional studies of muscles from Kit or Kitl (Kit ligand or stem cell factor) mutants. Recent studies have questioned the importance of ICC in enteric motor neurotransmission using the same models. In the present study we performed a detailed analysis of neuromuscular responses of fundus muscles of $W / W^{V}$ animals, and these studies were grouped on the basis of morphological determinations of the extent to which ICC-IM were reduced. An important and novel finding is that there are variable lesions in the ICC-IM population in $W / W^{V}$ fundus muscles, and different patterns of neurally-evoked motor responses were observed in the 2 groups of $W / W^{V}$ muscles (group 1 with no ICC-IM and group 2 with sparse but evident ICC-IM). In the $W / W^{V}$ group 1 mice, nitric oxide (NO)-dependent relaxation was absent, but in the $W / W^{V}$ group 2 muscles, inhibitory responses were still present, but reduced in magnitude. These data support previous studies of the importance of ICC-IM in nitrergic responses in the fundus, ${ }^{10,24}$ and suggest that use of Kit mutants should be accompanied by careful morphological analysis to determine the extent of the lesion in ICC. Our findings suggest the possibility that reports of retained nitrergic responsiveness in Kit mutants may have included animals with only partial lesions in the ICC population. ${ }^{14,15,17,25}$

Since the first experiments in which Kit mutants were used for functional studies of ICC, it was recognized that loss of ICC is incomplete in $W / W^{V}$ mice. ${ }^{1}$ For example, ICC-MY are largely lost in the small intestine, but ICC-DMP (the equivalent of ICC-IM in the small bowel) are not reduced greatly in numbers. The first report of ICC-IM loss in gastric muscles of $W / W^{V}$ mice reported absence of ICC-IM in the fundus, so it appears that $W / W^{V}$ group 1 was the predominant population sampled for morphological examination in that study. ${ }^{10}$ The reasons for the variable loss of ICC populations in $W / W^{V}$ mice are unclear at present, but genetic drift in the breeder population (i.e., $W /+$ or 
$W^{V} /+$ mice) with time or epigenetic regulation of Kit expression resulting from diet or environmental influences that could be factors. The differences in the post-junctional responses between $W / W^{V}$ groups 1 and 2 from this study and previously published studies by our group 9 support a possible change in Kit expression in these mutants.

The release of NO from enteric neurons is the predominant mechanism of fundus muscle relaxation, ${ }^{26-28}$ and relaxation responses are mediated through activation of the cyclic guanosine monophosphate (cGMP)-dependent mechanisms. ${ }^{18,26}$ The degree of activation of guanylate cyclase (the physiological receptor for $\mathrm{NO}$ in fundus muscles) in ICC versus SMC is controversial. If ample $\mathrm{NO}$ is released into the interstitium, it may diffuse freely to all cells in the vicinity of release sites. By immunofluorescence, ICC were shown to express $\alpha$ and $\beta$ isoforms of gunaylate cyclase necessary for functionality and responsiveness to $\mathrm{NO} .^{29,30}$ Synthesis of cGMP in ICC in response to nerve stimulation has also been demonstrated, and this synthesis was blocked by L-NNA. ${ }^{29,31}$ In comparison studies have failed to resolve guanylate cyclase and cGMP synthesis in response to nerve stimulation in SMCs. However, this could be a feature of lower, but possibly still effective, expression of guanylate cyclase, in SMCs and failure to resolve lower levels of guanylate cyclase and cGMP with immunohistochemical techniques. There is relatively little known about the concentrations of $\mathrm{NO}$ achieved in the interstitium after release from enteric inhibitory motor neurons and the actual concentrations that survive metabolism and reach guanylate cyclase receptors in different cell types in situ. For example, what is the radius of diffusion of effective concentrations of $\mathrm{NO}$ from individual varicosities? With higher concentrations of guanylate cyclase in ICC-IM and frequent close proximity of ICC-IM to nerve varicosities, transduction of nitrergic signals would seem favorable in ICC, however the availability of cellular neuroeffector mechanisms (e.g., ion channels, $\mathrm{Ca}^{2+}$ sequestration mechanisms and control of $\mathrm{Ca}^{2+}$ sensitization of the contractile apparatus etc) are also important factors in neurotransduction. New technologies are needed to evaluate these questions and determine the target cells responsible for post-junctional responses.

A recent study of the relative roles of ICC and SMCs in nitrergic relaxation utilized transgenic mice with cell-specific disruption of the gene encoding the $\beta_{1}$ subunit of guanylate cyclase (Gucy1b3). This study found that knocking down Gucy1b3 in either ICC or SMCs did not block nitrergic responses, but responses were greatly attenuated in mice in which Gucy1b3 was knocked down in both cell types. Thus, both ICC and SMCs were suggested as targets in mediation of $\mathrm{NO}$ relaxation in the gastric fundus. ${ }^{18}$ It may be that inhibitory responses in either cell type can compensate for loss of the inhibitory response in the other cell type, but loss in both disrupts nitrergic inhibition. A question remains about the extent of knockdown of Gucy1b3 in ICC versus SMCs. Substantial knockdown of gyanylate cyclase was demonstrated by immunohistochemistry, ${ }^{18}$ but as stated above guanylate cyclase was much more highly expressed in ICC-IM than in SMCs. Thus, a sub-complete knockdown of guanylate cyclase in SMCs might render these cells unresponsive to NO, but sub-complete knockdown of guanylate cyclase may leave ICC still responsive. In fact, the latter is equivalent to conditions in $W / W^{V}$ group 2 mice where sub-complete lesions in ICC-IM reduced, but did not abolish nitrergic responses. The remaining ICC-IM in group 2 muscles are equivalent to conditions in inducible knock-out mice in which some cells have only one floxed allele deactivated by Cre recombinase. The resulting heterozygotic nature of these cells, with a remaining functional allele, would support production of guanlylate cyclase and nitrergic responsiveness. Thus, the cell-specific inducible Cre mice in which Gucy1b3 is knocked down in ICC-IM may bear resemblance to $W / W^{V}$ group 2 mice with partial lesions in ICC-IM. Our study suggests that significant reductions in ICC-IM are capable of supporting nitrergic responsiveness, but when ICC-IM are lost, the fundus does not respond to $\mathrm{NO}$ released from motor neurons.

cGMP-dependent protein kinase-1 (Prkg1) is a critical downstream molecule in the $\mathrm{NO}$ signaling pathway. $\mathrm{NO}$ induces relaxation of the GI muscles via activation of Prkg1 and phosphorylation of a variety of targets. ${ }^{32-34}$ ICC express the $\beta$-isoform of Prkg1. ${ }^{35,36}$ In vivo genetic deletion of Prkg1 in ICC, resulted in significant reduction or abolition in NO-dependent responses. Further, there was a marked increase in gastrointestinal transit in these animals. ${ }^{36}$ Therefore the role of ICC in mediating NO-dependent responses in the GI tract is supported using the inducible Cre/loxP-based mouse models that have several advantages over other animal models used to date, with the caveat described in the previous paragraph. Since induction of Cre activity is performed in mature animals, chances for adaptive or compensatory mechanisms that occur often in animals carrying mutations from conception are reduced. ${ }^{36}$

Cholinergic (atropine sensitive) responses to nerve stimulation were enhanced in both groups of $W / W^{V}$ fundus muscles, suggesting enhancement in excitatory responses when ICC are absent or reduced. Others have also reported enhanced responses 
to excitatory nerve stimulation in $W / W^{V}$ muscles, but changes in baseline activity made the results of these studies difficult to interpret. $^{14,17}$ These authors suggested enhanced contractions were due to enhanced neurokinin responses due to increased $\mathrm{NK}_{1}$ receptors, however we did not find increases in $\mathrm{NK}_{1}$ receptors in $W / W^{V}$ muscles and atropine continued to block most of the excitatory response, as in wild-type mice. Only $\mathrm{M}_{3}$ muscarinic receptors were enhanced in $W / W^{V}$ muscles, and increased muscarinic receptors might have been partially responsible for enhanced cholinergic responsiveness.

Enhanced cholinergic responses in $W / W^{V}$ mutants that have reduced or loss of ICC are contradictory to previous studies using these mutants ${ }^{9}$ and to a more recent study where cholinergic excitatory junction potentials were absent in the colons of tamoxifen-treated $c-K_{i t}{ }^{\text {CreERT2-/+ }}, L S L-R 26^{\text {DATA/+ }}$ mice which carry a latent diphteria toxin A expression cassette and where ICC were depleted by approximately $50 \%$ following tamoxifen treatment. ${ }^{36}$

Our data corroborate a recent study of biochemical mechanisms activated by $\mathrm{ACh}$ released from motor neurons in wild-type and $W / W^{V}$ fundus muscles. ${ }^{37}$ That study also found potentiation of cholinergic excitatory responses in $W / W^{V}$ fundus muscles. Loss of most ICC-IM in $W / W^{V}$ mice led to augmented activation of post-junctional $\mathrm{Ca}^{2+}$ sensitization mechanisms in SMCs. In wild-type muscles only CPI-17 phosphorylation occurred in response to $\mathrm{ACh}$ released from motor neurons, whereas in $W / W^{V}$ muscles both CPI-17 and MYPT1 phosphorylation occurred, and these augmented responses began to mimic the responses to bath application of muscarinic agonists. It is possible that the close apposition of ICC-IM to enteric motor neuron varicosities compartmentalizes $\mathrm{ACh}$ released from neurons and leads to very high concentrations of junctional ACh. High concentrations of ACh would tend to hasten its metabolism by acetylcholine esterase. In the present study we observed a marked increase in excitatory responses in $W / W^{V}$ muscles compared to wild-type in response to neostigmine (Fig. 6). An up-regulation in M3 receptors might also contribute to the increased responsiveness of $W / W^{V}$ muscles. Inhibition of ACh degradation might increase the post-junctional concentration of $\mathrm{ACh}$, increase the volume into which ACh released from nerves diffuses, and lead to increased binding to smooth muscle receptors. Increased responses to neostigmine in $W / W^{V}$ muscles may also be enhanced by augmented $\mathrm{Ca}^{2+}$ sensitization in fundus muscles lacking ICC-IM.

We also observed a decrease in $\mathrm{NK}_{2}$ receptor expression and no change in $\mathrm{NK}_{1}$ receptor expression in the absence of ICC-IM.
The increase in excitatory responses in $W / W^{V}$ muscles was previously attributed to up regulated neurokinin responses. ${ }^{14} \mathrm{We}$ also noted an atropine resistant component of excitatory responses in $W / W^{V}$ muscles that was not as prominent in wild-type muscles (Fig. 3). However, the atropine resistant component (possibly due to neurokinins released at higher frequencies of stimulation) represented only a small fraction of the total excitatory response (i.e., $W / W^{V}$ group 1 AUC was $3.3 \%$ and $W / W^{V}$ group 2 was $0.89 \%$ compared to its corresponding wild-type control at $8 \mathrm{~Hz}$ ). These observations show that with the stimulus parameters utilized excitatory neurotransmission in the murine fundus is predominantly cholinergic.

In summary, the results from this study support the conclusion that ICC-IM are important mediators of inhibitory neurotransmission. Retention of even a small percentage of the ICC-IM population facilitates nitrergic responses, although diminished in amplitude. Excitatory regulation is more complicated. ICC-IM may also be quite important in mediating excitatory inputs, but remodeling of post-junctional cells and a greater sphere of influence of ACh recruit additional mechanisms in SMCs that are capable of sustaining cholinergic responses. Of course, responses may differ in other models of ICC-IM loss. For example, if these cells are lost from adult muscles, compensatory mechanisms may be less robust.

\section{Acknowledgements}

The Molecular and Morphology Core Laboratory was supported by an equipment grant from the NCRR for the Zeiss LSM5 10 confocal microscope (1 S10 RR16871) which was used for some of the immunohistochemical studies.

We are grateful for the technical expertise provided by Yulia Bayguinov, Byoung Koh and Lauren Peri for this study.

\section{Supplementary Materials}

Note: To access the supplementary tables mentioned in this article, visit the online version of Journal of Neurogastroenterology and Motility at http://www.jnmjournal.org/, and at doi: http://dx.doi.org/10.5056/jnm.2014.20.2.171.

\section{References}

1. Ward SM, Burns AJ, Torihashi S, Sanders KM. Mutation of the proto-oncogene c-kit blocks development of interstitial cells and elec- 
trical rhythmicity in murine intestine. J Physiol 1994;480(Pt 1): 91-97.

2. Torihashi S, Ward SM, Nishikawa S, Nishi K, Kobayashi S, Sanders KM. c-kit-dependent development of interstitial cells and electrical activity in the murine gastrointestinal tract. Cell Tissue Res 1995; 280:97-111.

3. Huizinga JD, Thuneberg L, Klüppel M, Malysz J, Mikkelsen HB, Bernstein A. W/kit gene required for interstitial cells of Cajal and for intestinal pacemaker activity. Nature 1995;373:347-349.

4. Ordög T, Ward SM, Sanders KM. Interstitial cells of cajal generate electrical slow waves in the murine stomach. J Physiol 1999;518(Pt 1):257-269.

5. Daniel EE, Posey-Daniel V. Neuromuscular structures in opossum esophagus: role of interstitial cells of Cajal. Am J Physiol 1984;246(3 Pt 1):G305-G315.

6. Ward SM, Sanders KM. Interstitial cells of Cajal: primary targets of enteric motor innervation. Anat Rec 2001;262:125-135.

7. Beckett EA, Takeda Y, Yanase H, Sanders KM, Ward SM. Synaptic specializations exist between enteric motor nerves and interstitial cells of Cajal in the murine stomach. J Comp Neurol 2005; 493:193-206.

8. Horiguchi K, Sanders KM, Ward SM. Enteric motor neurons form synaptic-like junctions with interstitial cells of Cajal in the canine gastric antrum. Cell Tissue Res 2003;311:299-313.

9. Ward SM, Beckett EA, Wang X, Baker F, Khoyi M, Sanders KM. Interstitial cells of Cajal mediate cholinergic neurotransmission from enteric motor neurons. J Neurosci 2000;20:1393-1403.

10. Burns AJ, Lomax AE, Torihashi S, Sanders KM, Ward SM. Interstitial cells of Cajal mediate inhibitory neurotransmission in the stomach. Proc Natl Acad Sci USA 1996;93:12008-12013.

11. Zhu MH, Kim TW, Ro S, et al. $\mathrm{A} \mathrm{Ca}^{2+}$-activated $\mathrm{Cl}^{-}$conductance in interstitial cells of Cajal linked to slow wave currents and pacemaker activity. J Physiol 2009;587(Pt 20):4905-4918.

12. Hwang SJ, Blair PJ, Britton FC, et al. Expression of anoctamin 1/TMEM16A by interstitial cells of Cajal is fundamental for slow wave activity in gastrointestinal muscles. J Physiol 2009;587(Pt 20):4887-4904.

13. Koh SD, Rhee PL. Ionic conductance(s) in response to post-junctional potentials. J Neurogastroenterol Motil 2013;19:426-432.

14. Huizinga JD, Liu LW, Fitzpatrick A, et al. Deficiency of intramuscular ICC increases fundic muscle excitability but does not impede nitrergic innervation. Am J Physiol Gastrointest Liver Physiol 2008;294:G589-G594.

15. Goyal RK, Chaudhury A. Mounting evidence against the role of ICC in neurotransmission to smooth muscle in the gut. Am J Physiol Gastrointest Liver Physiol 2010;298:G10-G13.

16. Bautista-Cruz F, Paterson WG. Evidence for altered circular smooth muscle cell function in lower esophageal sphincter of W/Wv mutant mice. Am J Physiol Gastrointest Liver Physiol 2011;301:G1059G1065.

17. Zhang RX, Wang XY, Chen D, Huizinga JD. Role of interstitial cells of Cajal in the generation and modulation of motor activity induced by cholinergic neurotransmission in the stomach. Neurogastroenterol Motil 2011;23:e356-e371.

18. Groneberg D, Lies B, König P, et al. Cell-specific deletion of nitric oxide-sensitive guanylyl cyclase reveals a dual pathway for nitrergic neuromuscular transmission in the murine fundus. Gastroenterology 2013;145:188-196.

19. Nangle MR, Cotter MA, Cameron NE. An in vitro investigation of aorta and corpus cavernosum from eNOS and nNOS gene-deficient mice. Pflugers Arch 2004;448:139-145.

20. Chlopicki S, Kozlovski VI, Lorkowska B, Drelicharz L, Gebska A. Compensation of endothelium-dependent responses in coronary circulation of eNOS-deficient mice. J Cardiovasc Pharmacol 2005;46: 115-123.

21. Koh BH, Roy R, Hollywood MA, et al. Platelet-derived growth factor receptor-alpha cells in mouse urinary bladder: a new class of interstitial cells. J Cell Mol Med 2012;16:691-700.

22. Kwon JG, Hwang SJ, Hennig GW, et al. Changes in the structure and function of ICC networks in ICC hyperplasia and gastrointestinal stromal tumors. Gastroenterology 2009;136:630-639.

23. Monaghan K, Baker SA, Dwyer L, et al. The stretch-dependent potassium channel TREK-1 and its function in murine myometrium. J Physiol 2011;589(Pt 5):1221-1233.

24. Beckett EA, Horiguchi K, Khoyi M, Sanders KM, Ward SM. Loss of enteric motor neurotransmission in the gastric fundus of $\mathrm{Sl} / \mathrm{Sl}(\mathrm{d})$ mice. J Physiol 2002;543:871-887.

25. Sivarao DV, Mashimo HL, Thatte HS, Goyal RK. Lower esophageal sphincter is achalasic in $\mathrm{nNOS}^{-/-}$and hypotensive in $\mathrm{W} / \mathrm{W}^{\mathrm{V}}$ mutant mice. Gastroenterology 2001;121:34-42.

26. De Man JG, De Winter BY, Herman AG, Pelckmans PA. Study on the cyclic GMP-dependency of relaxations to endogenous and exogenous nitric oxide in the mouse gastrointestinal tract. Br J Pharmacol 2007;150:88-96.

27. Yoneda S, Suzuki H. Nitric oxide inhibits smooth muscle responses evoked by cholinergic nerve stimulation in the guinea pig gastric fundus. Jpn J Physiol 2001;51:693-702.

28. Vetri T, Bonvissuto F, Marino A, Postorino A. Nitrergic and purinergic interplay in inhibitory transmission in rat gastric fundus. Auton Autacoid Pharmacol 2007;27:151-157.

29. Iino S, Horiguchi K, Nojyo Y, Ward SM, Sanders KM. Interstitial cells of Cajal contain signalling molecules for transduction of nitrergic stimulation in guinea pig caecum. Neurogastroenterol Motil 2009;21:542-550, e13.

30. Iino S, Horiguchi K, Nojyo Y. Interstitial cells of Cajal are innervated by nitrergic nerves and express nitric oxide-sensitive guanylate cyclase in the guinea-pig gastrointestinal tract. Neuroscience 2008; 152:437-448.

31. Shuttleworth CW, Xue C, Ward SM, de Vente J, Sanders KM. Immunohistochemical localization of 3',5'-cyclic guanosine monophosphate in the canine proximal colon: responses to nitric oxide and electrical stimulation of enteric inhibitory neurons. Neuroscience 1993;56:513-522.

32. Hofmann F. The biology of cyclic GMP-dependent protein kinases. J Biol Chem 2005;280:1-4.

33. Pfeifer A, Klatt P, Massberg $\mathrm{S}$, et al. Defective smooth muscle regulation in cGMP kinase I-deficient mice. EMBO J 1998;17:30453051.

34. Xue L, Farrugia G, Miller SM, Ferris CD, Snyder SH, Szurszewski $\mathrm{JH}$. Carbon monoxide and nitric oxide as coneurotransmitters in the enteric nervous system: evidence from genomic deletion of biosynthetic enzymes. Proc Natl Acad Sci USA 2000;97:1851-1855. 
35. Salmhofer H, Neuhuber WL, Ruth P, Huber A, Russwurm M, Allescher HD. Pivotal role of the interstitial cells of Cajal in the nitric oxide signaling pathway of rat small intestine. Morphological evidence. Cell Tissue Res 2001;305:331-340.

36. Klein S, Seidler B, Kettenberger A, et al. Interstitial cells of Cajal integrate excitatory and inhibitory neurotransmission with intestinal slow-wave activity. Nat Commun 2013;4:1630.

37. Bhetwal BP, Sanders KM, An C, Trappanese DM, Moreland RS, Perrino BA. $\mathrm{Ca}^{2+}$ sensitization pathways accessed by cholinergic neurotransmission in the murine gastric fundus. J Physiol 2013; 591(Pt 12):2971-2986. 